\title{
SOME GAPS IN OUR KNOWLEDGE OF HEREDITY.
} By Herbert J. WebBer, Professor of Experimental Plant Biology,
Cornell University.

\section{ADVANCE IN KNOWLEDGE OF HEREDITY.}

The last decade has witnessed a tremendous advance in our knowledge of heredity, but still the gaps in our knowledge remain the most important part of the subject. Could we map out the entire field and show only those portions which have been surveyed, as is done in soil maps, the surveyed areas representing discovcred facts would, we fear, appear infinitesimally small. Manifestly the discussion of these gaps must at best be very meager and imperfect and the writer contemplates here only a disjointed discussion of a few isolated cases.

The discovery of Mendel's law and the experimental knowledge which has accrued since that time has entirely changed our viewpoint and the discussions of heredity today with reference to hybridization would be meaningless jargon to Nageli and Naudin, who half a century ago did so much to advance our knowledge of hybrids. In the enthusiasm first attending the discovery of Mendel's law, the investigators saw in it the solution of all our diffculties and the reduction of breeding work by hybridization to a fixed rule which could be followed calmly, with certainty of results. Chaos had been reduced to order. The extended experiments which have followed the discovery of Mendel's law cannot be said to have decreased its importance, but at every point the necessity for further study and care in interpretation has been demonstrated. What, at first, seemed to be a simple law easy of interpretation, is daily bedoming more complex.

\section{REVERSION AND PURITY OF THE GERM CELL.}

One of the fundamental principles of Mendel's law is the so-called purity of the germ cell, with reference to the presence in it of the anlagen or heredity units representing allelomorphs, or paired, characters. The application of the law in its simplicity would predicate that a germ cell, pollen grain sperm or egg cell, in its formation would receive only the anlage of one character of a certain contrasted pair of characters. It was soon perceived that cases of atavism or reversion would throw doubt on the truth of this hypothesis. Many of the cases of reversion, it has been claimed, are due to the reappearance of recessive characters which were supposed to have been bred out. As a recessive character becomes rare in a race under selection it may be several or many generations before a recessive sperm meets a recessive egg and permits the appearance of the character. Bateson states that "a proof that any given reversionary character is merely a recessive can be got at once by observing that the reverting individuals on being fertilized with themselves or with their like, will breed true and at least will not reproduce the types 
from which they were extracted." Whether this would prove the matter the writer considers doubtful, unless the extracted supposed recessive were retained under cultivation and observation for many years, to prove definitely that it would not revert to the dominant type. Several interesting cases of this nature have come under the writer's observation, two of which he will describe here in some detail.

Many years ago, at least thirty or forty years, as nearly as the writer has been able to learn, there was cultivated in the southern United States a cotton know as "Nankeen," supposed to have been imported from China, and characterized principally by having reddish brown fiber. The demand for this fiber fell off with the introduction of improved methods of dyeing and its cultivation was entirely abandoned. Only the old planters of the South remember when this cotton was cultivated. When the writer began the study of cotton for the United States Department of Agriculture, in 1898, he learned of this variety through literature and began inquiry as to sources where seed could be obtained. Extensive inquiry failed to reveal any place where the variety had been retained in cultivation, even as a novelty. As the writer's rescarches on cotton were extended, the cotton specimens and oddities sent to the Department of Agriculture were referred to him, and among these in 1903 a specimen of seed with brownish fiber was received, which was taken from a single plant in a field of ordinary white upland cotton, and which from its oddity attracted the attention of the grower. These seeds were planted in 1904 and produced four plants, each of which was in general like ordinary upland cotton, but differed in having lint which was light yellowish brown. The open-fertilized seed from these four plants, which were grown in a field with ordinary varieties, was preserved and about onefifth of an acre was planted the next year, 1905, the seed of each plant being planted separately. The plants produced in this second generation under observation were very variable. In the progeny of two plants about half of the individuals produced reddish brown lint of about the same color and character as the original Nankeen. These plants were rather different from the other plants and the lint not only differed in color, but was also shorter and more silky, and did not "fluff" or spread out on drying in the sun as does the lint of ordinary cotton. The other plants in the row had lightbrown lint about midway in color between the Nankeen and the ordinary white-linted sorts. The progeny of the other two plants produced only individuals bearing the light-brown intermediate color. The further experiments with these cottons showed that the light-brown intermediate color could be produced in an apparently pure strain and also that the dark Nankeen-colored plants could be bred to a pure strain. Rather unfortunately the experiment was conducted primarily for its practical value and no actual counts of numbers and no hand pollinations were made. However, the evidence desired here is just as certain as it would be had such data been preserved. 
Since this first plant was received the writer has learned of at least two other cases of the sudden appearance of brown-linted plants of this nature in fields of ordinary cotton in widely different parts of the country, but their occurrence is very rare and they always attract attention as the pickers always notice them.

How are we to explain the occurrence of these brown-linted variations? Doubtless when the Nankeen was cultivated, the ordinary upland became hybridized with it to some extent and we would naturally look upon the reappearance of such plants as reversions, and this is the view the writer would surely take. If they are reversions can the phenomenon be explained simply as due to the presence of a recessive character which, from its rarity, fails to meet a recessive mate and thus fails to show except in these very rare cases? The writer does not believe that such an explanation can account for the phenomenon.

In considering the bearing of such a case it must be remembered that cotton is largely self-fertilized, only from 5 to 10 per cent. of the seed being ordinarily cross-fertilized. Thus if it could be considered as a recessive character the plants possessing this character would always be largely self-fertilized and the progeny should thus show the character in its purity regularly every year or until the character had been entirely bred out. Again, the evidence shows that the character is not recessive, but of equal strength or potency with the white lint, crosses coming intermediate in color. Thus, even assuming that all of the seed produced by such reverting plants was crossed with ordinary white-linted sorts, the yellowishbrown lint would be exhibited the next year as an intermediate heterozygote color, and would certainly be observed more commonly.

After starting observations in this line the writer observed other cases of considerable interest. In hybrids which he had under selection of upland cotton (Gossypium hirsutum) with Sea Island cotton ( $G$. barbadense) an occasional plant was observed which had light-brownish lint, only a suggestion of the color being present when observed. About thirty to forty thousand hybirds of the above combination have been under the writer's observation each year for the last six years, so that he has had abundant opportunity to observe such variations as each plant has passed under his personal inspection. Three of these hybrids showing slight brownish tinge of color were preserved and their seed planted. In each case a number of plants were produced having the dark reddish-brown lint similar to the Nankeen cotton, but the other characters in this case were not always those of the Nankeen. The dark-brown color was here mainly associated with long lint. In some few cases, however, typical Nankeen plants were produced, the reversion extending to all characters. This type of reversion on crossing is not uncommon in other plants and in some cases is known to occur even when types of absolute purity are crossed. Bateson says of such reversionary forms, "They never breed true in the first generation-the $F_{1}$ generation as we call it-but in the $F_{2}$ generation 
there must in all ordinary cases be a small but definite percentage of reversionary individuals which are then purebred and thenceforth able to breed true. As we now can prove, the reappearance of the ancient characteristic is caused by the meeting together of distinct elements, long parted. In some unknown way these two factors "let each other off." Both factors must be present. together in order that the feature in question may be developed."

While in some cases which have been investigated such an explanation may hold, the writer cannot so interpret the appearance of the Nankeen color in cotton which has come under his observation. Had we only the case of this reversion under hybridization, we might so interpret it, but the same occurrence in the pure upland cotton could not be so explained. The writer is strongly inclined to the view that any cotton plant, or certainly the majority of any which might be selected and isolated, would under rare conditions show this variation or reversion. The old and now supposedly meaningless expression, "that there is a "strain' of brown lint in all of our ordinary cottons,". about expresses the writer's idea.

In the course of cotton cultivation through many years, unquestionably there has been much mixing of races and species, and in our American upland cotton the writer believes that the heritage of this brown strain is practically universally present and may become segregated and manifest itself under certain rare conditions and also may be brought out by hybridization.

Another similar reversion in cotton which has been studied by the writer is a reversion to what growers call "okra-leaved" cotton, which is characterized by having deeply divided leaves with 3 to 5 narrow linear lanceolate lobes. Previous to the Civil War, between 1840 and 1860 , such a variety was cultivated to some extent, but the writer has not been able to learn of its cultivation since the war. Apparently all or at least many of the varieties of upland cotton now cultivated in the United States occasionally show a reversion to this type of leaf. The writer first learned of the occurrence of such reversion through growers who in general believed them to he the result of hybridization with okra. The writer and one of his assistants, Mr. Edson, at first assuming the possibility of such a hybridization, though thinking it very improbable, made numerous crosses of okra with cotton and the reciprocal combination, but obtained no indication of fertility between the two plants which are but distantly related. Iater the writer had the good fortune to find two of these okra-leaved reversions or sports and was able to cultivate them. One of these plants was found in a field of Commander cotton, a long-staple upland variety having lint from $1 \frac{3}{8}$ to $11 / 2$ inches long and a small boll. The plant showing the reversion or sport was like the Commander in type of plant, boll and lint, apparently varying from the Commander only in having the deeply divided leaves with narrow lobes. The same was true of the other reversion which was found in a field of Jones' Improved 
cotton. Jones' Improved is a big-bolled race with short lint - and large seed. The reversion was like Jones' Improved in all characters except that it had the deeply divided leaves with the narrow lobes. Some of the seed from each of these plants was planted the next year, 1904, and in each case the plants grown were almost entirely like the mother types, that is, Commander, with okra leaves and Jones' Improved with okra leaves.

The same reversion was found by Mr. A. W. Edson, one of the writer's assistants, in King cotton, a very early upland cotton with short lint and small boll and characteristic branching and shape of plant. Mr. Edson planted seed from this reversion and found it to reproduce its characters in marked degree. In this case, as in the ones studied by the writer, the reversion was in the character of the leaf only, the plants in all other regards being like King, the mother race. Mr. Edson cuntinued to plant this type for several generations, finding that it continued to reproduce its characters without marked change. The okra-leaved strain grown by Mr. Edson has been used by Dr. D. N. Shoemaker in crossing back onto ordinary upland races with the result, so Dr. Shoemaker informs the writer, that the okra-leaved character contrasted with the less deeply divided broad-lobed upland leaf proves to segregate in Mendelian proportions, the okra-leaved character being recessive.

These cases appear from such evidence as we have to be true reversions. Can they be explained as recessives, owing the rarity of their occurrence to the fact that recessive eggs do not in fertilization meet similar recessive sperms? The fact that unbagged seed in each of the three cases studied produced almost wholly plants of the same type as the reversion, shows that here, as in ordinary cotton, the flowers are mainly self-fertilized, and thus if the recessive character is present in any plant it would be in heterozygote form and such heterozygote plants, the following year, owing to the selffertilization, should produce a considerable number of pure recessives. The wide distribution of this type of reversions would show that the character is generally present in races of upland cotton. Its rare occurrence, however, shows quite conclusively that it cannot be explained as simply a rare recessive character.

A number of similar cases of reversion to characters apparently long lost have come under the writer's observation, but space will not permit further illustrations. It seems to the writer, from the evidence at his command, that we are forced to conclude that a race apparently purebred, and certainly remaining pure through many generations, may nevertheless carry in it the potentiality of producing other ancestral characters which have apparently been bred out. It would seem that the protoplasmic units, or anlagen, if we may so call them, representing the visible character and the ancestral character must be carried together from cell generation to cell generation and seed generation to seed generation, acting together ordinarily and showing only the new character, till some 
shock produced by abnormal conditions or by crossing segregates the ancestral unit and allows it to become manifest.

Cases similar to the above have been cited by Castle and Allen, where our conception of the purity of the germ cell must at least be modified. These writers state "that a mosaic gamete, on uniting in fertilization with a recessive gamete, does not lose its identity nor undergo resolution into its constituent parts." 1 They bring forth evidence from the standpoint of reversion to show that the conception of gametic purity must at least be modified. The deductions made by Castle and Allen, if correctly understood by the writer, are almost identical with the conclusion expressed by him in a paper presented before the Society of Plant Morphology and Physiology, at the Washington Meeting, December 28, 1902. The claim was then made by the writer that many cases of atavism to characters of distant ancestors show that the anlage of the character must have been present in the germ cells for several generations and not have shown itself in any of the progeny. The following case was then cited:

Numerous hybrids have been made by the writer of a variety of upland cotton (Gossypium herbaceum) known as Klondike with an ordinary strain of Sea Island cotton (G. barbadense). Upland cotton ordinarily has seeds which after removal of the lint are covered with short, fuzzy hairs; in some varieties, however, there are wanting, the seeds being smooth and black. The smooth, fuzzy sorts have become very much mixed so that most upland races vill form some few seeds nearly smooth. The Klondike variety was bred by a very careful planter, Mr. W. A. Clark, by carefully selecting only the smooth, black seeds every year and planting them in an isolated field. This careful selection was continued for a number of generations and resulted in the production of the Klondike, which uniformly gives smooth, black seeds. The Sea Island parent also has smooth, black seeds, this being one of the characteristics of the species. The first generation $F_{1}$, hybrids of which quite a number were grown, all had black seeds, in the second generation $\mathrm{F}_{2}$, however, quite a number of the hybrids had fuzzy seed like the original upland from which the Klondike was bred. This shows clearly that the anlage or protoplasmic unit representing the fuzzy seed character must have remained latent for several generations without exerting itself.

Orange and lemon growers by selecting buds from branches that show few thorns have produced clons that are thornless. If seedlings are grown from these, they are, however, invariably thorny, which is the character of the wild type of the species. The anlagen representing the thomy character had thus not been bred out by the vegetative or clonal selection, but simply temporarily suppressed or masked.

Again, as pointed out by the writer in his paper before the Society of Plant Morphology and Physiology, gametic purity is contradicted by the known facts regarding the fixation of hybrids showing intermediate characters, i. e., characters representing a point midway between the characters of the parents. These characters, which would be termed heterozygote characters in Correns' and Bateson's terminology, we could not expect to obtain in stable races if Mendel's principles held strictly true, because when the germ cells of the hy-

1 The Heredity of Albinism. Proc. Am. Acad. Arts and Sci. 38, p. 617. 
brid were formed, the anlagen representing the two contrasted characters would separate according to the Mendelian ratio. The segregation in the second generation into one or the other of an allelomorph pair is certainly not true in the case of the length of staple of cotton hybrids, as an examination of probably 50,000 hybrids have shown all gradations of intermediates between the two-inch staple of the Sea Island and the one-inch of the upland. These gradations of length in the first, second, third, and fourth generation hybrids can be shown in practically all degrees. Again, when single plants are isolated and bred thus inter se, they give great variations, but can be bred to fixed types, having almost any length of staple desired.

It is not a difficult matter to find instances of intermediate characters resulting from hybrids, that have been bred into thoroughly fixed races. The various races of cotton and corn furnish numerous instances of this sort. The group of cotton races known as the long staple uplands are presumably all of hybrid origin, being hybrids of Sea Island cotton (Gossypium barbadense) with upland cotton ( $G$. hirsutum). Among these are the races known as Griffin, Allen Improved, Allen Hybrid, Cooks Long Staple, Simms, Sunflower, etc. These hybrids all have a fiber about intermediate in length and fineness between the two parent species. The boll in all has been bred to the upland parent type as has been also the plant in habit mainly. The White Cap Dent races of corn are undoubtedly hybrids of white and yellow races which in the first generation hybrids very commonly have yellow sides with whitish caps. This, as near as the writer can judge with our present understanding of colors, is a typical heterozygote character, being a resultant of a commingling of the two parent types. Judging from experiments conducted by the writer there would seem to be no doubt but that this heterozygote character has been fixed in the several existing White Cap Dent races of corm. The writer believes from his knowledge of cultivated races of plants that there is no doubt but that such heterozygote types are very commonly selected and fixed into stable races which regularly generation after generation exhibit the heterozygote type.

It may be objected that the above cases are possibly to be explained as cases of blended inheritance and are thus not Mendelian. The most typical case of the fixation of a typical Mendelian heterozygote character known to the writer is found in the Voorhees Red Sweet corn bred by Professor Halstead. This race is a hybrid of Black Mexican sweet corn, having a purplish black endosperm, with the Egyptian sweet corn, having an amber-colored endosperm, These two characters which normally segregate in Mendelian proportion, produce the dark purplish red color of the Voorhees Red as a heterozygote color, yet this color Professor Halstead has bred into a fixed race by selection. The writer has carried out a similar selection to fix a heterozygote color with a hybrid of Black Mexican with Stowells Evergreen, and while the type has not reached fixity, 
a very large percentage of the intermediate light violet-colored kernels are now produced.

If this is true the two units representing the character pair must become permanently united and act together as a new character and this is what the writer believes does occur. By the gradual selection of only those plants which show the desired heterozygote type this permanent union is apparently affected. If a variation exists in any of the hybrids towards the formation of more of the heterozygote types this would naturally be selected out as the most prepotent type and used as the select parent for the next generation. The writer's idea in regard to the union of the anlagen representing different characters is that they follow a law or rule somewhat similar to a chemical radical, the anlagen forming a character pair going together ordinarily as a single compound anlage, analagous to a chemical radical such as $\mathrm{NH}_{4}$ in many compounds. One of these anlagen may be normally dominant in the Mendelian sense so that the anlage of the recessive character though continually present with it does not show until some unknown condition causes a segregation of the two elements, when suddenly the recessive character, which perhaps has not shown for generations, suddenly appears in pure form.

IS THERE A CUMULATIVE EFFECT OF SELECTION

A question which has recently been raised and one which is of the greatest importance to breeders is whether there is a cumulative effect of selection such as was claimed by Darwin. The methods of plant-breeders until recently have been based on this assumption, though it must be admitted without any very accurate foundation. The intricate systems devised by Hallett, Hays, and othersin breeding wheat based on selecting the best individuals of a race each year had as their objects the production of new and improved races through the supposed cumulative action of the selection. Now we find Nilsson and DeVries advocating what may be termed the method of single-type selection. DeVries says:

The main discovery is that most of our ordinary agricultural crops are composed not only of elementary species, as was long known before, but that each cultural variety contains hundreds of sharply defined types. These are widely distinct from one another in botanical characters as well as in those properties which determine their utility from the breeder's point of view, and thus they afford a rich material for selection.

This claim, which is in line with the mutation theory, would if carried out change the method of selection which is now generally pursued. Professor J. B. Norton, now of Cornell University, who has been working for a number of years in the breeding of oats, independently arrived at the same conclusion several years ago and changed his method in conformity. In accordance with this belief, as held by Nilsson, DeVries and Norton, what the breeder should do is simply to carefully study the types existing in a variety or race and select out those which in his judgment possess the 
characters of greatest value which are most likely to give improved types. The work with these types after the first selection would consist simply in testing them in comparison with each other and with the best known varieties to determine which type was the superior one and also to increase the seed of those found to be the best. During this test the breeder would naturally examine the progeny of each type and in those thought to be valuable, and would rogue out such plants as were not true to the type selected. In plants which are more or less cross-fertilized, such roguing would have the effect of weeding out the crosses and hybrids.

The breeder's primary work would then be limited mainly to making the first choice, which would be assumed to be a mutation and would be expected to come true to type aside from such impurities as may have been introduced by accidental crossing, etc. Are we in position from the knowledge at hand to advocate this method? Should breeders accept this method generally there would be no selection of the best individuals through numerous generations, but all plants of the type desired would be retained, heavy vielders and light yielders; yield being understood as a varietal characteristic.

The evidence which has accumulated since the announcement of the Mutation Theory and the history of the origin of many of our cultivated varieties apparently show conclusively that mutations have played an important part in plant improvement. It is still, however, questionable in the writer's mind whether the selection and isolation of high-yielding individuals annually does not increase our chance of discovering still higher yielders, which would never have been discovered had only the first selections been made.

As an illustration, in 1903 the writer carefully combed and examined the lint of about 400 individuals of the Pride of Georgia cotton, a big-bolled early race of upland. This examination was made with the hope that individuals could be found showing a tendency to produce rather longer fiber which would give a starting point for the production of a new long-fibered race. The fiber was found to range in length from $\frac{7}{8}$ of an inch to about 1 1-16 with a mean of about 1 inch. These variations were doubtless all what we would now term fluctuations. The range of variation in length was not thought sufficient to justify a selection for increased length of lint, but 25 of the best-yielding early plants were selected to begin a breeding experiment for increased yield. In 1904 and 1905 from 150 to 200 of the best-yielding plants were selected each year, taking them as is ordinarily done from the best-yielding progenies. In making these selections no attention was paid to lint length except to pull the seeds of a few locks apart on each plant to observe hastily the length of the staple, which can be very closely estimated by one trained in the work. None but good yielding plants were examined and in these the only attempt was to see that the staple was an inch or more in length. This caution was thought necessary even though the selection was not intended to produce long-stapled sorts, because almost universally in cotton, heavy yield is strongly corre- 
lated with short lint, and it was desired simply to keep the lint up to a good short-staple standard.

During 1904 and 1905 the staple was observed to be good, but no exceptional variations were noticed. In making the selection in 1906, however, it began to be noticed that the staple was varying considerably in length and plants were noticed with $11 / 4$-inch staple. In 1907 the fact came out very prominently that the character of the staple was being rapidly changed. In this season many plants were noticed with $11 / 4$-inch staple and some with $13-8$-inch staple. In 1906 and 1907 no difficulty would have been experienced in finding many plants which would have furnished a fine basis for beginning a long-staple selection. The variation in length of lint had certainly been greatly increased. It would seem that by the hasty selection exercised with regard to lint length intended simply to keep the strain up to good lint standard, the equilibrium of the variety had been broken as it were and the range of variation increased in apparently a progressive degree. To establish this fact definitely would, of course, require an extended statistical study, but the writer and Mr. R. C. Keenan, a practical cotton breeder, who aided him in the work, feel just as sure of this conclusion as they would if the figures were before them.

The gradual increase in the oil and protein content of corn in the experiments conducted at the Illinois Station seem to indicate a cumulative result in the selection. Much higher percentages are now found than could be found in the beginning of the experiments or than are now found in the original variety which has not been under selection. The mutationist would doubtless say that mutations had probably been produced and selected, but the apparent fact remains that the increase has been gradual. It would seem that here the selection had resulted in increasing the maximum, and that the maximum was gradually increasing as a result of the selection. The writer is well aware that the case of the sugar beet could be cited on the other side to show that a selection carried on for half a century and on a tremendous scale has not apparently sufficed to increase the maximum.

This question is one which remains with the experimental breeders to settle if possible, and there is probably no question in practical breeding on which it is more desirable to secure further evidence. If the single type selection method is the correct one with all plants as well as with self-fertilized cereals, the breeder is wasting valuable time in making continuous selections. On the other hand, if there is a cumulative action in selection, in following the single-type selection method the breeder would be losing the benefit of the cumulative action which could be obtained by making selections every generation. 


\section{EFFECT OF INBREEDING ON METHODS OF CORN SELECTION.}

Another point which the writer desires to emphasize, on which more evidence is desired, is the question of the effect of different degrees of close fertilization on the vigor of different plants and especially corn. It has been found by various investigators that self-fertilization in corn causes great loss of vigor, and if continued for a few generations results in almost complete sterility. Some time after the organization of the Illinois Corn Breeders' Association, when the selection by the ear-to-row method had been in operation for several years, the breeders began to find that they were not getting the increased yields which they had expected. The matter was carefully discussed and the conclusion reached that the failure was due to the effect of too close inbreeding, this conclusion being based on the experiments showing the detrimental effect of self-fertilization. Elaborate methods were then devised to prevent inbreeding and ensure the crossing of as distantly related plants of the same strain as possible. These methods in general include the detasseling of those individuals to be used as mothers from which seed is to be saved and the careful arrangement of rows in the breeding plat in order to get unrelated individuals together. The question the writer wishes to raise is whether there is any real reason for all of this trouble. The writer knows of no experiments showing that the crossing of even brothers and sisters in corn leads to decreased fertility and vigor. Corn is in a slight degree proterandrous, but nevertheless, there is some self-fertilization of plants with their own pollen and this undoubtedly leads to decreased vigor. In planting by the ear-to-row method, the plants in any one row would all bear the relation to each other of full brother and sister or half brother and sister, depending on whether or not they had all been fertilized with pollen from the same sire or different sires; according to the law of chance, certainly much less than one-quarter would be full brothers and sisters. Assuming that two ears planted in rows side by side were full brother and sister (which might be the case), and that all the kernels on each ear had been fertilized by the same sire (which certainly would never be the case), then the relationship between the individuals of the two rows would be half brother and sister. If they had been fertilized with different sires the different individuals in the rows would be cousins, and this is the closest relationship which the individuals of two rows side by side, planted by the ear-to-row method, could ever have. If no rows were discarded and all planting were in sequence they would probably rarely be closer than first cousins, and where, as in practice, many progenies are discarded, they would quite commonly be much more distantly related than first cousins.

If no detasseling is practiced and plants are planted by the earto-row method, any individual ear in a row would have about equal chance of getting pollen from other individuals in the same row (brother or half brother) and from individuals in other rows (cousins 
or more distantly related), with chances in favor of more than half being pollinated from other rows. There would also be chance of some little self-pollination. To avoid the possibility of self-pollination and fertilization with brothers or half brothers it is probably well to detassel those rows from which seed is to be saved, but the writer doubts whether it is necessary to go to any trouble in planting to get distantly related strains together. It seems to him, that on finding our method too simple and that cross fertilization must be insured, we jumped to the other extreme and made our methods more difficult than the fàcts now known demand. In-and-in-breeding with animals when accompanied by careful selection has been of great value and probably will ultimately prove of value in plants also.

\title{
RECENT ADVANCES IN THE THEORY OF HEREDITY.
}

\author{
By C. B. Davenport, Cold Spring Harbor, N. Y.
}

The Medelian theory of heredity still remains as the foundation for modern research in heredity, but recent careful and extensive statistical studies show that the simple Mendelian Formula is often profoundly modified. Even Bateson, who represents an extreme school of Mendelians, states as a result of his studies on inheritance of polydactylism in poultry that there is another factor imposed on the Mendelian, giving a divergence from simple results. Miss McCracken and Castle have found the same thing, and in my report before the Breeders' Association last year (page 134) I told of the result of crossing a single and a paired comb which gives a $\mathrm{Y}$ in comb in $F_{1}$, in which the proportion of the median element varies from 5 to 95 per cent. Now when the median element is 50 per cent of the whole comb in both parents the proportions of single and paired comb in $\mathrm{F}_{2}$ accords with Mendelian expectation; but if the stem of the $\mathrm{Y}$ is long-75 to 95 per cent of the comb-the proportion of children with a single comb will, instead of 25 per cent, be 50 per cent; and if the stem is short ( 40 per cent of the whole), the percentage of single-combed offspring falls to 19 . Here we have two opposing tendencies represented by the single comb and the paired comb. If the paired comb is in the ascendancy in any individual, the germ cells formed in that individual seem not to have an equal number of single and paired comb determiners, or else there is unequal potency of the characters, so that when $\mathrm{Y}$ comb is expected single comb appears because of the greater potency of the median element over the paired.

Now the result that is yielded by the $\mathrm{Y}$ comb is only a vivid picture of a very common result in heredity, and I propose to cite other instances. I, too, have worked with polydactyl poultry and find, like Bateson, clear evidence of its fundamentally Mendelian nature in heredity since extracted $\mathrm{RX} R$ give only 4-toed offspring. But whereas the Silky 6-toed condition mated to the normal number 